\title{
Flood flow at the confluence of compound river channels
}

\author{
T. Ishikawa ${ }^{1}$, R. Akoh ${ }^{1} \&$ N. Arai $^{2}$ \\ ${ }^{I}$ Department of Environmental Science and Technology, \\ Tokyo Institute of Technology, Japan \\ ${ }^{2}$ Kajima Corporation, Japan
}

\begin{abstract}
The implementation of a compound cross section is often used to enhance a river system by increasing the channel capacity for high water and stabilizing the stream during low water. The design of the confluence is one of the most difficult aspects of the implementation of a compound channel because the streamlines during high water may deviate from the banks of the low-water channel depending on the inflow conditions. This paper reports a field study on flood flow at the confluence of the Tone River and Watarase River in Japan, wherein aerial photograph analysis and numerical flow simulation were employed. The surface velocity field was obtained by stereo image analysis of the aerial photographs taken at a flood peak in 1981. The analysis revealed the occurrence of flow divergence and convergence across the banks of the lowwater channel as well as flow stagnation around the tree communities in the high-water channel. A quasi-3D shallow water model with an unstructured triangular mesh system was used to simulate the flow field. The drag force of the tree communities was also taken into consideration based on the results of a field survey. The simulation fairly well reproduced the surface flow field obtained by image analysis. The calculated difference between the streamlines at the surface and bottom of the water suggested that dispersive stress may have significantly affected the flow near the banks of the low-water channel, especially around the tree communities.

Keywords: flow field, river confluence, compound channel, field study, aerial photo analysis, numerical flow simulation, quasi-3D shallow water model.
\end{abstract}




\section{Introduction}

The design of a channel for smooth merging of streams at a river confluence is an important aspect of river improvement works, and many researchers have conducted fundamental flume tests to investigate the flow structure produced by the interaction between the streams of two river channels [1-3]. Numerical flow models have also been used to reproduce the observed flow structures [4, 5] from the viewpoint of fluid mechanics. However, the obtained results are not very practical because the test flumes were often straight and had rectangular cross sections, which amount to an oversimplification of the configurations of real rivers.

Compound cross sections have been widely used in recent river improvement works to increase the channel capacity for high water and stabilize the stream during low water. However, the streamlines at the confluence of such channels during high water may deviate from the banks of the low-water channel depending on the inflow conditions. Inappropriate design of the channel may thus result in flow stagnation and the inducement of local sedimentation, patchy vegetation growth, and flow concentration, which may pose a threat to the embankments. Although accumulated field data could be used to check and improve the configuration of confluent channels, there is limited opportunity for field measurements in high water condition of large rivers.

A numerical flow model that has been verified by field data is useful for examining the effectiveness of a channel design under various hydraulic conditions. This paper reports a field study on flood flow at the confluence of the Tone River and Watarase River in Japan, the results of which were used to develop a numerical flow model for practical simulation. The surface velocity field was obtained by stereo image analysis of a series of aerial photographs taken at the peak of the largest flood that occurred in 1981. A quasi-3D shallow water model with an unstructured triangular mesh system was used to simulate the flow field on the compound topography. The effectiveness of the simulation model was evaluated by comparing the calculated surface velocity field with the results of analysis of the aerial photographs.

\section{Study site}

The study site is indicated by the rectangle in fig. 1. The Tone River has its source in the central mountains of Japan's main island, and flows across the alluvial plain on the north side of Tokyo, eventually discharging into the Pacific Ocean. The river originally flowed into Tokyo Bay, until 400 years ago, when its course was diverted eastward to join the two large water systems that were used to develop the water transport and the irrigation system for farmlands on the alluvial plain. One of the water systems, namely, the Watarase River, joins the middle reach of the Tone River. The design of the river reach, including the confluence, is one of the important aspects of the river basin management because the flood water of the Tone River tends to follow its former course toward the city of Tokyo, as actually happened in 1947. 


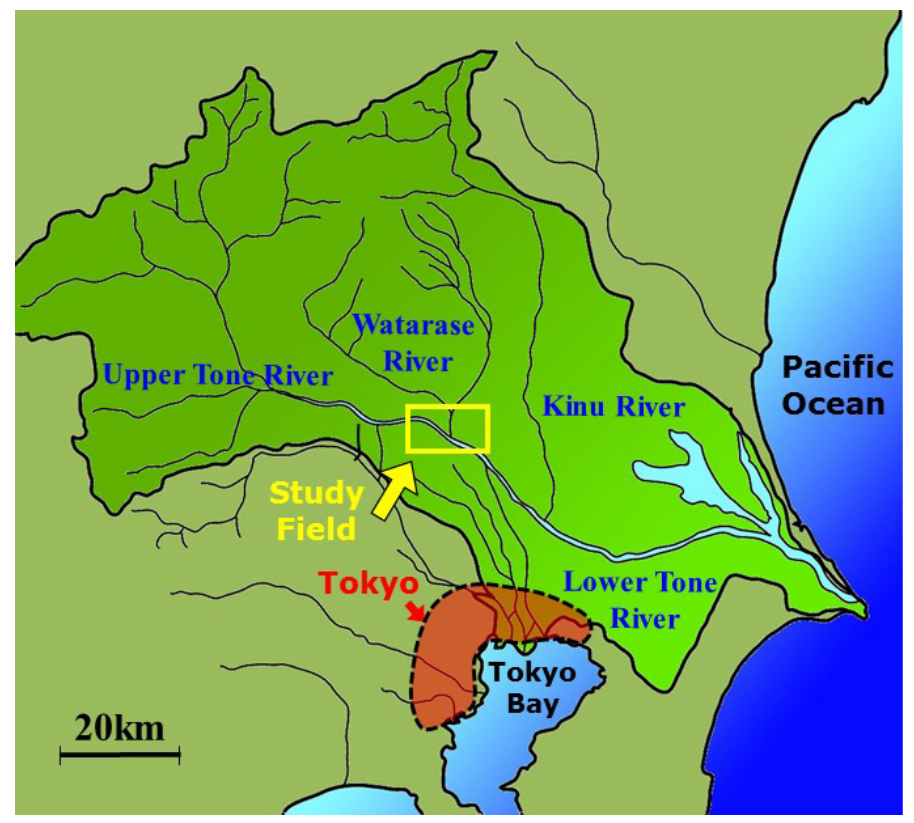

Figure 1: The Tone River Basin.

Fig. 2 shows the channel configuration at the confluence, where KP denotes Kilo Post, which is the distance from the river mouth for the Tone River and its confluence point for the Watarase River. The ground of the high-water channel is used as a pasture, but some reed colonies and tree communities remain along the banks of the low-water channel. Fig. 3(a)-(c) show the channel cross sections at the three lines in fig. 2, where HWL is the high water level for the design flood discharge based on a return period of 200 years, and FWL is the water level at the time of shooting the aerial photographs used for the analysis of this study.

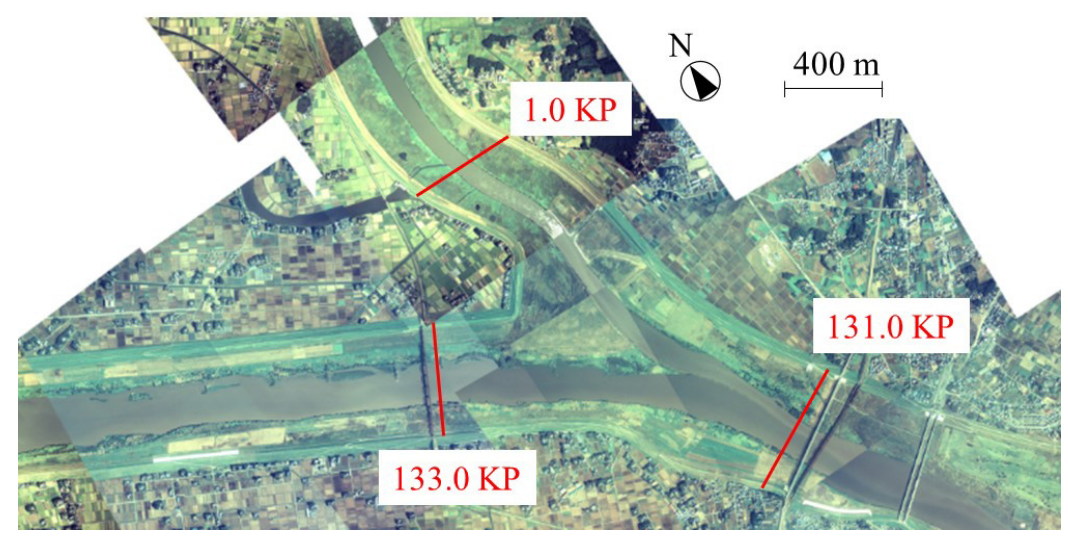

Figure 2: Study site. 
(a) $131.0 \mathrm{KP}$

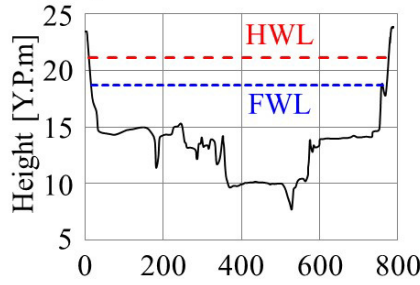

(b) $133.0 \mathrm{KP}$

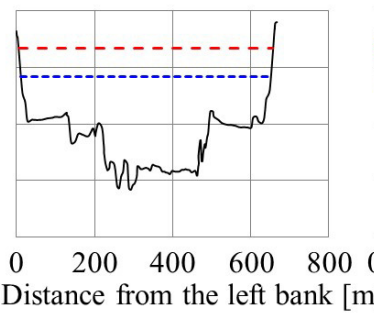

(c) $1.0 \mathrm{KP}$

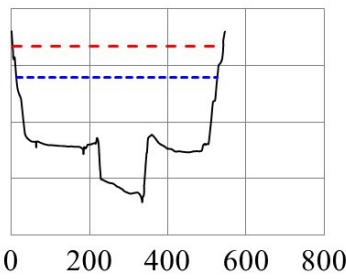

Figure 3: Channel cross sections.

\section{Aerial photograph analysis}

Table 1 gives the shooting conditions of the aerial photographs. A series of vertical photographs were taken along the course of the Tone River. Fig. 4 shows the coverage of each photograph. Fig. 5 shows the hydrograph obtained at the water gauge station (a triangle in fig. 4). The aerial photographs were taken around the peak of the flood as indicated by the vertical red band.

Table 1: Shooting conditions of the aerial photographs.

\begin{tabular}{|c|c|}
\hline Date & August 23, 1981 \\
\hline Time & $16: 32: 13-16: 32: 40$ \\
\hline Altitude & $1,460 \mathrm{~m}$ \\
\hline Scale & $1: 10,000$ \\
\hline Time interval & $7 \mathrm{~s}$ \\
\hline Overlap ratio & $70 \%$ \\
\hline
\end{tabular}

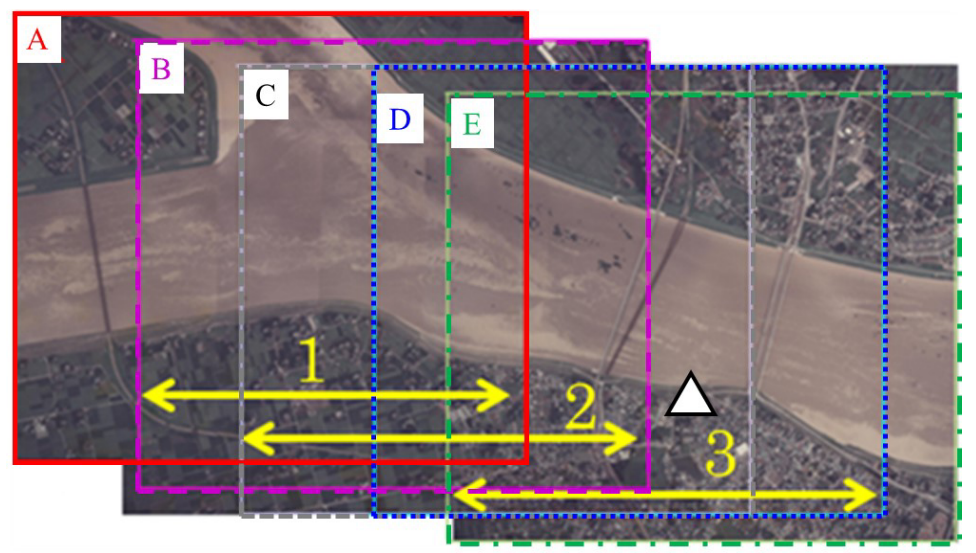

Figure 4: Coverage of the aerial photographs. 


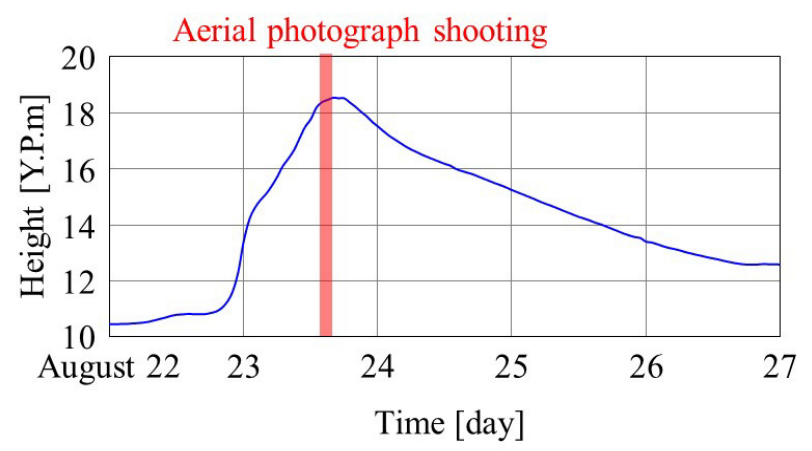

Figure 5: Flood hydrograph at the Kurihashi station (130.39 KP).

The water surface velocity field was obtained using the technique of stereo image analysis proposed by Minoura et al. [6]: The aerial photographs show the fine color patterns formed by the suspended sediment and bubbles on the water surface. The primary data set of the surface velocity vectors were obtained by image correlation analysis of each pair of consecutive photographs for the overlapped area. The data contained local errors due to the mismatch of similar color patterns. The results of the primary analysis were merged with the original images on the PC, and the error vectors were detected and interactively corrected by the Cameron effect [7] through the stereo glass located above the PC screen.

Fig. 6 shows the results for three sets of photographs. The red, blue, and green arrows respectively indicate the velocity vectors obtained from the photographs $\mathrm{A}$ and $\mathrm{B}, \mathrm{B}$ and $\mathrm{C}$, and $\mathrm{C}$ and $\mathrm{D}$ shown in fig. 4. Fig. 7(a) and (b) compare the transverse profiles of the longitudinal velocities at the two sections shown in fig. 6 , where the two sets of photographs were obtained. The profiles at both sections agree fairly well with each other, and the discrepancies may be attributed to velocity fluctuation during the shooting time of consecutive photographs, $7 \mathrm{~s}$ (table 1).

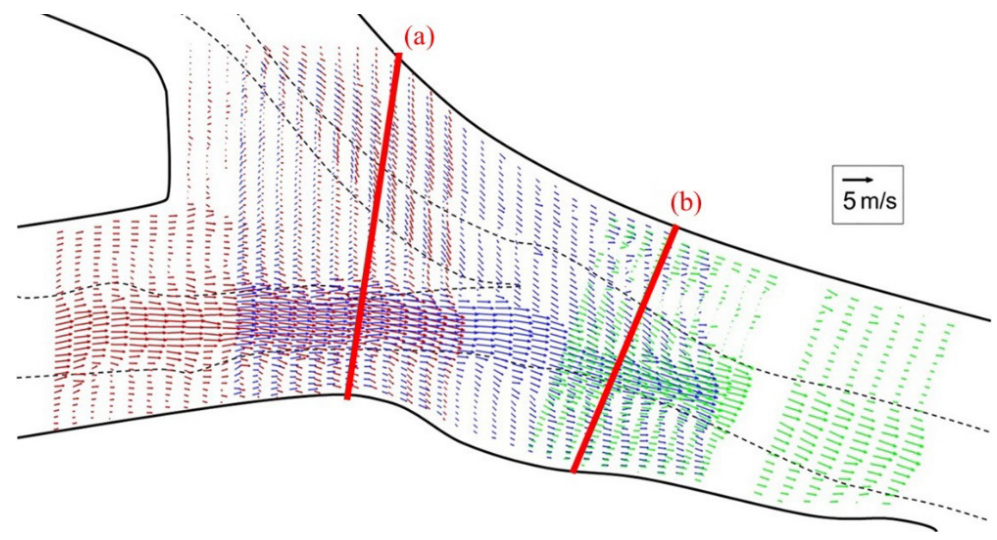

Figure 6: Surface velocity vectors obtained by analysis of aerial photographs. 
(a)

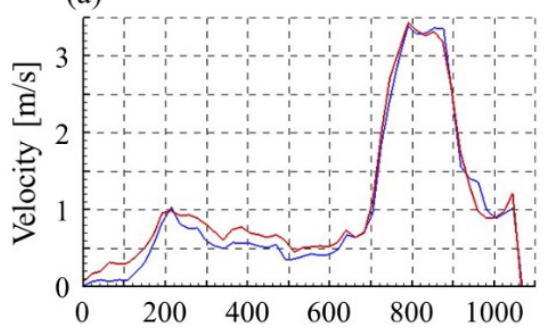

Distance from the left bank [m] (b)

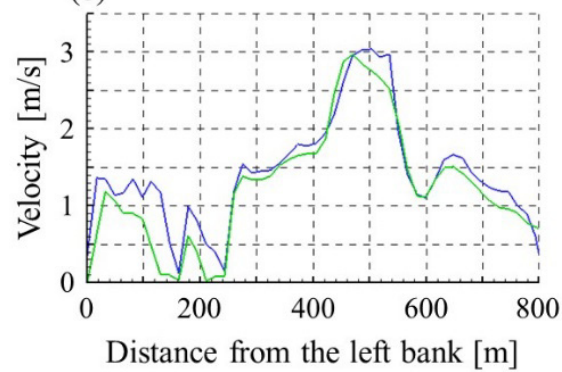

Figure 7: Comparison of the velocity distributions obtained from consecutive photographs. Left: at cross section (a), Right: at cross section (b).

\section{Numerical simulation}

\subsection{Model equation}

The governing equations of the model are the continuity equation for incompressible fluid and the momentum equations with the assumption of hydrostatic pressure, which are respectively as follows:

$$
\begin{gathered}
\frac{\partial u}{\partial x}+\frac{\partial v}{\partial y}+\frac{\partial w}{\partial z}=0 \\
\frac{\partial u}{\partial t}+u \frac{\partial u}{\partial x}+v \frac{\partial u}{\partial y}+w \frac{\partial u}{\partial z}=-g \frac{\partial H}{\partial x}+\frac{\partial}{\partial z}\left(\varepsilon_{V} \frac{\partial u}{\partial z}\right)+\frac{C_{D}}{h} u \sqrt{u^{2}+v^{2}} \\
\frac{\partial v}{\partial t}+u \frac{\partial v}{\partial x}+v \frac{\partial v}{\partial y}+w \frac{\partial v}{\partial z}=-g \frac{\partial H}{\partial x}+\frac{\partial}{\partial z}\left(\varepsilon_{V} \frac{\partial v}{\partial z}\right)+\frac{C_{D}}{h} v \sqrt{u^{2}+v^{2}}
\end{gathered}
$$

where $t$ is the time, $(x, y, z)$ are the Cartesian coordinates ( $z$ is the upward direction), $(u, v, w)$ are the corresponding velocity components, $H$ is the water level, $\varepsilon_{v}$ is the vertical kinematic eddy viscosity, $g$ is the gravitational acceleration, and $\mathrm{C}_{D}$ is the coefficient of the drag force induced by the immersed bulky vegetation. [8]:

The linear function of the horizontal velocity profile is assumed as follows

$$
\left(\begin{array}{l}
u \\
v
\end{array}\right)=\left(\begin{array}{l}
u_{0} \\
v_{0}
\end{array}\right)+\left(\begin{array}{l}
u_{1} \\
v 1
\end{array}\right) \cdot f\left(\frac{z}{h}\right), \quad f\left(\frac{z}{h}\right)=\frac{z}{h}-\frac{1}{2}
$$

where $\left(u_{0}, v_{0}\right)$ are the depth-averaged velocities, $\left(u_{1}, v_{1}\right)$ are the deviations of the velocities from $\left(u_{0}, v_{0}\right)$, and $h$ is the local water depth. The dispersive stress is expressed as follows: 


$$
\frac{1}{h} \int_{0}^{h}\left(u v-u_{0} v_{0}\right) d z=u_{1} v_{1} \int_{0}^{1}\left(\zeta-\frac{1}{2}\right)^{2} d \zeta=\frac{1}{12} u_{1} v_{1}=\lambda u_{1} v_{1}
$$

If another expression of the velocity deviation term in eqn. (4) is assumed, the parameter $\lambda$ will change, but the range of the variation would not be sufficiently large for possible profile assumptions.

The Galerkin method was applied to eqns (1), (2), and (3) to derive five equations corresponding to the unknown variables $h, u_{0}, v_{0}, u_{1}$, and $v_{1}$ :

$$
\int \text { (Equation) } \cdot(\text { Weight function }) d z=0
$$

Table 2 gives the combination of the governing equation, weight function, and principal unknown variable for each Galerkin equation. In the calculation, the vertical averaged kinematic eddy viscosity $\varepsilon_{v}$ was introduced using the SDS turbulent model [9].

Table 2: Governing equation, weight function, and principal unknown variable.

\begin{tabular}{|c|c|c|}
\hline Governing equation & Weight function & Principal unknown variable \\
\hline \hline$(1)$ & 1 & $h$ \\
\hline$(2)$ & 1 & $u_{0}$ \\
\hline$(2)$ & $f(\mathrm{z} / \mathrm{h})$ & $u_{1}$ \\
\hline$(3)$ & 1 & $v_{0}$ \\
\hline$(3)$ & $f(\mathrm{z} / \mathrm{h})$ & $v_{1}$ \\
\hline
\end{tabular}

\subsection{Numerical solver}

The finite volume method using an unstructured triangular mesh system was used to solve the Galerkin equations (eqn. (5)). The mesh system can approximate a compound topography using fewer grid points compared to the rectangular mesh system. The grid point layout was automatically designed using ANSYS ICEM CFD based on points along the banks of the low-water channel and the embankments of the high-water channel.

Single values of the variables $h, u_{0}, v_{0}, u_{1}$, and $v_{1}$ were assigned to each triangular cell. The equations of the time evolution were obtained by integrating the Galerkin equations over each cell and applying the Green-Gauss theorem. In the process, the flux across the boundary was estimated using Roe's approximate Riemann solver [10].

\subsection{Flow resistance}

The land surface condition in the high-water channel was identified by stereo image analysis of aerial photographs taken in 1980. Fig. 8 shows the results of the analysis. 


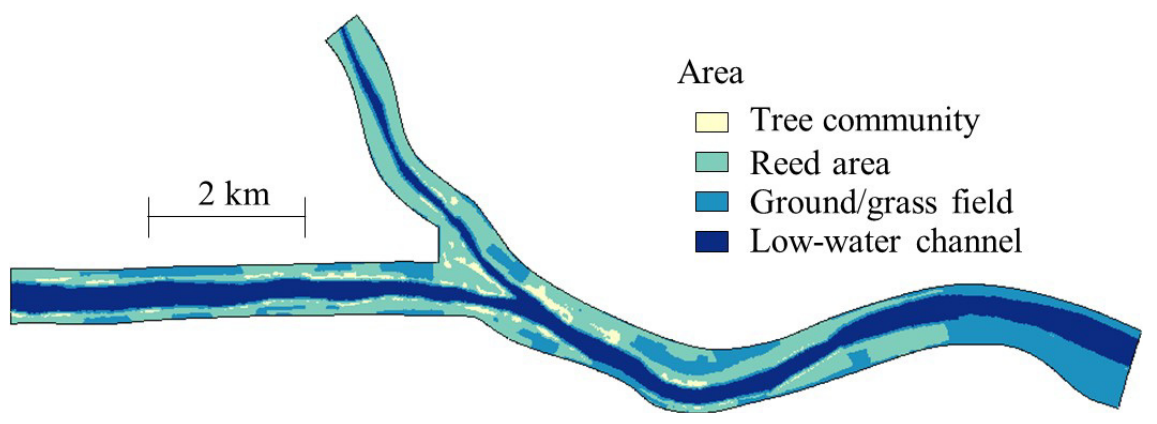

Figure 8: Land surface condition in the computation domain.

Two types of resistances to the flow were considered, namely, the ground surface roughness and the drag force of the immersed bulky vegetation. The assumed Manning's coefficients of surface roughness are as listed in table 3 [6]. The drag force of the tall tree communities was taken into consideration. Based on the results of a field survey of the tree crown profile and leaf density [11], the typical profile of the drag coefficient $C_{D}$ was determined to be as follows:

$$
C_{D}=\left\{\begin{array}{lc}
0.002 & \zeta<0.98 \mathrm{~m} \\
-0.011 \zeta^{2}+0.064 \zeta-0.058 & 0.98 \mathrm{~m} \leq \zeta \leq 4.0 \mathrm{~m} \\
0.0 & \zeta>4.0 \mathrm{~m}
\end{array}\right.
$$

where $\zeta$ is the height from the ground surface.

Table 3: Manning's coefficient.

\begin{tabular}{|c|c|}
\hline Area & Manning's coefficient \\
\hline \hline Tree community & 0.130 \\
\hline Reed area & 0.052 \\
\hline Ground/grass field & 0.038 \\
\hline Low-water channel & 0.017 \\
\hline
\end{tabular}

\subsection{Calculation conditions}

The flow computation covered the $15 \mathrm{~km}$ reach between 123.0KP and138.0KP along the Tone River and the $3.5 \mathrm{~km}$ reach between $0.0 \mathrm{KP}$ and $3.5 \mathrm{KP}$ along the Watarase River. The length of the typical mesh constructed by ANSYS ICEM CFD was about $12 \mathrm{~m}$, and the total number of grid points was 133,669 . The ground level at each grid point was determined by interpolation of the cross section data at every $0.5 \mathrm{KP}$. The discharges from the upstream sections of the Tone River and Watarase River were respectively set to 6,160 and $1,736 \mathrm{~m}^{3} / \mathrm{s}$ based on the records of the river administration office. The water surface elevation at the downstream section was set to $16.8 \mathrm{YP} \mathrm{m}$ based on available records of the water gauge located at the section. The calculation was initiated 
under the stationary condition using a water surface elevation of $16.8 \mathrm{YP}$ m over the entire area, and was continued using time increments of $0.1 \mathrm{~s}$ for $18 \mathrm{~h}$ until a steady flow field was developed.

\section{Results and discussions}

Fig. 9 shows the calculated water surface velocity. As can be observed, the major flow characteristics determined from the aerial photograph analysis (fig. 6) are reproduced fairly well: (a) The flow in the low-water channel of the Tone River diverges to the left, spreads over the flood plain between the two rivers, and flows into the low-water channel of the Watarase River. (b) Another branch just before the junction point flows to the right and increases the velocity along the right embankment. (c) Beyond the upstream section, the stream center of the Watarase River shifts toward the left bank. (d) The flow in the low-water channel of the Watarase River is accelerated by the inflow from the floodplain between the two rivers. (e) The flow in the high-water channel on the left is separated by the tree community after the junction, resulting in increased velocity along the left embankment.

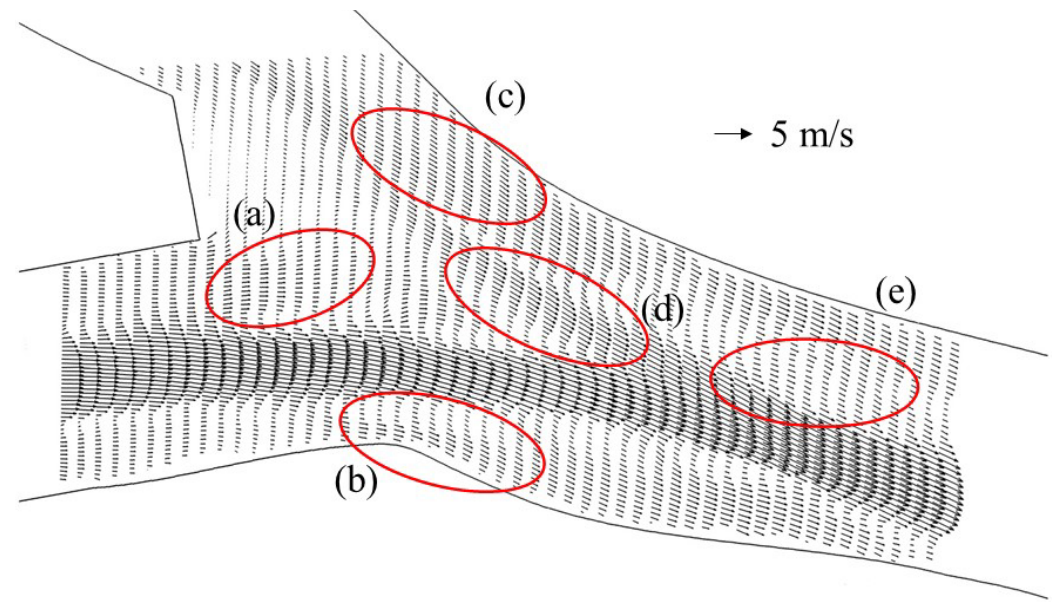

Figure 9: Calculated surface velocity vectors.

Fig. 10 shows the streamlines on the water surface and the channel bed, as obtained by integrating the streamline equation:

$$
\frac{d y}{d x}=\frac{v}{u}
$$

where $(x, y)$ are the horizontal coordinates and $(u, v)$ are the velocity components. The two streamlines almost agree with each other, with the differences in the areas highlighted by circles. The following can be observed: (a) The surface water from the floodplain flows along the left side of the low-water channel of 
the Watarase River, whereas the bottom water flows along the right side, suggesting a helicoid flow in the channel. (b) The bottom water flows at a sharp angle from the low-water channel above the right high-water channel, resulting in flow concentration along the right embankment. (c) The bottom water flows above the left high-water channel and enters the tree community.

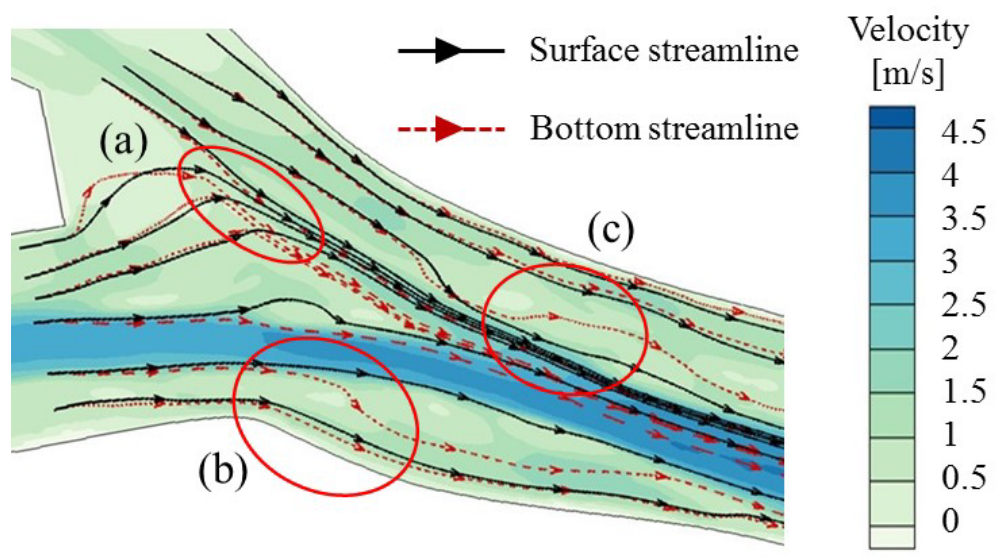

Figure 10: Streamlines on the water surface and channel bed.

Fig. 11 shows the detailed streamlines in region (c) in fig. 10. The distribution of the tree communities are indicated in light yellow. The initial points are common to the two types of streamlines. The bottom streamlines cross the lowwater channel bank with large amplitude, suggesting that the sedimentation is caused by the secondary current.
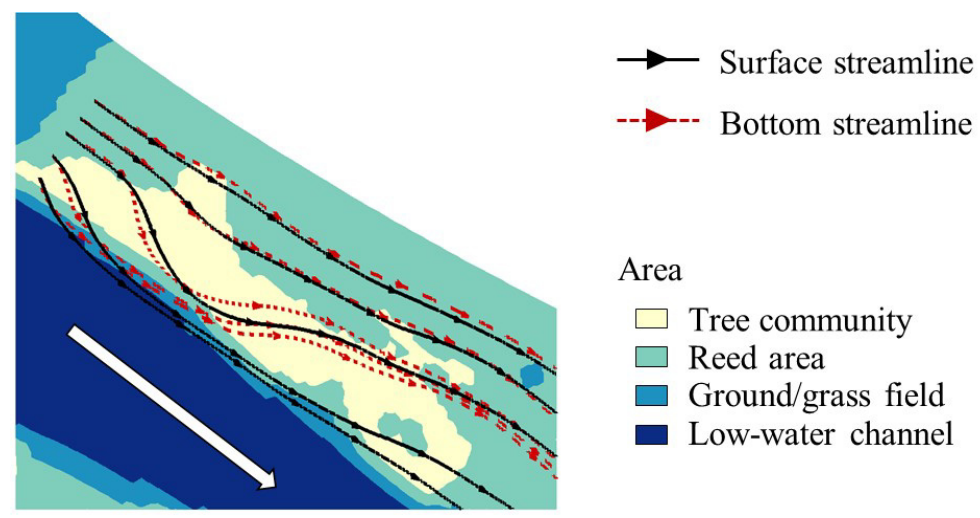

Area

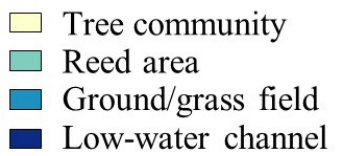

Figure 11: Difference between the streamlines on the water surface and the channel bed near the tree community. 


\section{Concluding remarks}

A quasi-3D shallow water model was used together with an unstructured triangular mesh system to reproduce the flow at the confluence of compound channels. The computation results were in fairly good agreement with the surface velocity field obtained by aerial photograph analysis. The computation results suggested that the tree communities near the banks of the low-water channel caused the bottom water to flow into the high-water channel, resulting in increased sedimentation and further growth of vegetation.

The quasi-3D flow model is capable of approximating 3D flow with comparatively low calculation cost. The combination of aerial photograph analysis and numerical flow analysis using the quasi-3D shallow water model is thus practical and useful for river channel management.

\section{Acknowledgement}

This research was supported by JSPS KAKENHI Grant Number 24560618.

\section{References}

[1] Mosley, M.P.: An experimental study of channel confluences, J. Geology, 84, pp. 535-562, 1976.

[2] Best, J.L. and Reid, I.: Separation zone at open-channel junctions, J. Hydr. Eng., 110, pp. 1588-1594, 1984.

[3] Rhoads, B.L. and Sukhodolov, A.N.: Field investigation of threedimensional flow structure confluences: 1 . Thermal mixing and timeaveraged velocities, Water Resour. Res., 37(9), pp. 2411-2424, 2001.

[4] Huang. J. Weber, L.J. and Lai, Y.G.: Three-dimensional numerical study of flows in open-channel junctions, J. Hydr. Eng., ASCE, 128, pp. 268280, 2002.

[5] Miyawaki, S., Constantinescu, G., Rhoads, B.L. and Sukhodolov, A.N.: Changes in three-dimensional flow structure at a river confluence with changes in momentum ratio, River Flow 2010, pp. 225-232, 2010.

[6] Minoura, Y., Ishikawa, T. and Yoshida, K.: Flood flow analysis on aerial photos by image correlation method with support of stereo visualization, 16th IAHR-APD, pp. 999-1004, 2008.

[7] Cameron, H.L.: The measurement of water current velocity by parallax method, Photogrammetric engineering, No. 1, 1952.

[8] Finnie, J., Donnell, B., Letter, J. and Bemard, R.S.: Secondary flow correction for depth-averaged flow calculation, J. Hydr. Eng., ASCE, 125, No.7, pp. 848-863, 1999.

[9] Nadaoka, K. and Yagi, H.: Shallow water turbulence modeling and horizontal large eddy computation of river flow, J. Hydr. Eng., ASCE, 124, pp. 493-500, 1998. 
48 River Basin Management VIII

[10] Roe, P.L.: Approximate Riemann solvers, parameter vectors, and difference schemes, J. Comput. Phys., 43, pp. 357-372, 1981.

[11] Arai, N.: Development of quasi-3D model for confluent flow at river junction, Master Thesis, Tokyo Institute of Technology, 2014. 